\title{
Promoción de la salud a través del arte: una experiencia en torno a la crisis medioambiental
}

\author{
Paola María PADILla VERA ${ }^{1}$ \\ paopave@gmail.com
}

Enviado: 19/05/2011

Aceptado: 12/10/2011

\section{RESUMEN}

El presente artículo propone al arte como herramienta para la intervención desde la promoción de la salud, para lo cual, primero, se reflexiona sobre las diversas concepciones que existen en torno a qué es la salud, haciendo explícita una definición propia de dicho concepto para, posteriormente, exponer a grandes rasgos la aparición y evolución de la promoción de la salud en el mundo con el fin de enmarcar la propuesta metodológica. Finalmente, para ejemplificar la propuesta, se describe su puesta en marcha en el taller "Reflexionando sobre residuos sólidos" llevado a cabo en septiembre de 2010, en la Universidad Autónoma de la Ciudad de México, con estudiantes de licenciatura.

Palabras clave: Promoción de la salud., arte, crisis medioambiental.

\section{Referencia normalizada}

PADILLA VERA,.P. M. (2011). "Promoción de la salud a través del arte: una experiencia en torno a la crisis medioambiental”. En Arteterapia: Papeles de arteterapia y educación artística para la inclusión social Vol.: 6. Páginas 219-235. Madrid. Servicios de publicaciones UCM.

\section{SUMARIO}

Una reflexión en torno a la definición de salud. La Promoción de la Salud y el arte. El tiradero de "basura": una primera experiencia desde la promoción de la salud a través del arte. A manera de nota final... Referencias bibliográficas.

\begin{abstract}
Health promotion through art: An experience about environmental crisis

This article proposes art as a tool for intervention from health promotion, for which, first, it reflects on the diverse views that exist about what health is, making explicit its own definition. Then it will be outlined the emergence and development of health promotion around the globe to acknowledge its methodology. Finally, the implementation of the proposal is described at the workshop "Reflecting on solid waste" held in September 2010, at Universidad Autónoma de la Ciudad de México, where undergraduates participate.
\end{abstract}

Keywords: Health Promotion, art, enviromental crisis.

\section{SUMMARY}

Reflecting on health definition. Health Promotion and art. The garbage collector: a first experience from the health promotion through the art. Final note. References.

\footnotetext{
${ }^{1}$ Profesora-Investigadora de tiempo completo, Universidad Autónoma de la Ciudad de México.
} 


\section{UNA REFLEXIÓN EN TORNO A LA DEFINICIÓN DE SALUD}

Es necesario hacer explícita la propia concepción sobre la salud cuando se pretende proponer acciones que se relacionen con ella; sin embargo resulta ser una difícil tarea considerando que es un fenómeno multifactorial y multidimensional que cada cultura ha interpretado de acuerdo con su cosmovisión y, por lo tanto, ha puesto énfasis en aquellos aspectos que para ella son esenciales, resultando esto en una gran diversidad de definiciones, algunas de las cuales son, aparentemente, contradictorias e irreconciliables entre sí.

¿Qué es la salud? Tal vez sea una de las preguntas más difíciles de responder entonces, debido a que no sólo la salud misma se encuentra determinada por lo cultural, sino también las representaciones que sobre ella tenemos y, por lo tanto, las definiciones que hemos construido al respecto.

De esta manera, tenemos que en la actualidad confluyen diferentes visiones en torno a lo que es la salud - y su contraparte, la enfermedad - que, a su vez, se manifiestan en gran diversidad de prácticas a lo largo de todo el mundo. Algunas de estas construcciones se derivan de la cosmovisión de grupos sociales antiguos, mientras que otras se han ido instaurando a partir de los descubrimientos y avances en la investigación de la ciencia médica de la cultura occidental moderna, imponiéndose como la postura hegemónica que forma la base de la mayor parte de las acciones institucionales relacionadas con este tema.

Desde mi punto de vista, cada perspectiva existente sobre el tema se centra en un factor distinto que interviene en ese fenómeno que llamamos salud, así como en una dimensión diferente; es decir, en sólo un pequeño fragmento de la totalidad del ser humano, mas en casi ningún caso se estudian las relaciones complejas que se encuentran en juego de manera holística. Así, ha sucedido que se observan partes del todo y desde ahí se construyen los postulados teóricos y las intervenciones metodológicas que se desprenden de ellos, dando como resultado una visión incompleta del tema en cuestión, además de generar aparentes contradicciones que han llevado precisamente a la imposición de unas miradas sobre otras.

Un ejercicio que me gusta hacer en mis clases de Introducción a la Promoción de la Salud es el siguiente: tomando cualquier cosa que esté a mi alcance en el salón, me sitúo en el centro y le pido a uno de mis estudiantes que se encuentra frente a mí que me lo describa, luego le pido a otro que se encuentra a mi derecha que haga exactamente lo mismo y, posteriormente, le pido a alguno de la izquierda que repita el proceso. A cada uno le digo que me está mintiendo, que lo que me está describiendo de ese objeto es falso, por lo que o me confrontan diciéndome que estoy mal o haciendo simplemente gestos de desaprobación. ¿Por qué les digo que están mal? ¿acaso lo están? Lo digo porque yo estoy viendo una cara de ese objeto que ellos no ven, pero asimismo ellos están viendo una parte de ese objeto que yo no veo, así que el decirles que es mentira lo que me dicen no es porque en realidad yo lo piense así, sino que es la forma más fácil que he encontrado para que comiencen a cuestionarse sobre el hecho de tomar como verdades absolutas nuestras propias ideas - $\mathrm{o}$ las de ciertos autores - sin considerar que estamos viendo sólo una parte del todo y 
que, por lo tanto, no puede ser La Verdad. En este ejercicio puede verse incluso cómo, aparentemente, lo que cada uno va describiendo del mismo objeto puede parecer contradictorio e irreconciliable, pero no es así en realidad, porque se está refiriendo a un pequeño fragmento. ¿Quién tiene la razón? ¿quién está mintiendo? Todos y ninguno. Todos tienen la razón porque están describiendo lo que ven, sin lugar a dudas, y todos están mintiendo porque lo toman como el todo cuando no lo es. Ninguno tiene la razón absoluta porque está describiendo sólo una parte y no el todo y ninguno está mintiendo porque, en efecto, habla de lo que ve. De aquí la conclusión de que conjuntando las posturas fragmentarias podríamos tener una descripción un poco más completa del objeto y, seguramente, aún así no podríamos decir que sería La Verdad Absoluta sobre el mismo, porque aún nos faltaría una visión del interior, desde arriba, desde abajo y desde muchos otros factores y dimensiones que se relacionan con él.

Los objetos que suelo utilizar son relativamente "sencillos", tales como una botella de agua o una envoltura de galletas o frituras y resulta que a pesar de ello nos llevan a la reflexión sobre lo complejo que resulta describirlos, definirlos y analizarlos, por lo que cabe preguntarnos lo que ocurre con la definición de salud, siendo un objeto de estudio abstracto que no podemos ver, oler, sentir, probar o escuchar por sí mismo, sino sólo en sus manifestaciones.

Desde mi perspectiva, la salud, como ya lo mencioné anteriormente, es un fenómeno multifactorial y multidimensional complejo. Algunos la han definido como un estado, otros como un proceso y otros como un recurso. Algunos la estudian desde lo biológico, otros desde lo psicológico y otros desde lo social (y aquí, además, desde lo micro y macro social). Algunos se centran en las manifestaciones en el organismo, otros en los grupos sociales.

El ser humano constantemente se relaciona a partir de diferentes dimensiones, tales como la biológica, la social, la psicológica y la espiritual, y se encuentra en una relación dialéctica con múltiples factores tanto externos como internos, en la que ellos lo determinan, pero también él puede modificarlos y, por lo tanto, determinarlos.

La dimensión biológica se refiere a todos aquellos procesos bioquímicos y fisiológicos que se dan en todos los sistemas que componen al organismo, a saber: respiratorio, digestivo, nervioso, circulatorio, etc. y que se encuentran determinados tanto por factores endógenos (es decir, por ejemplo, la genética, las sustancias químicas producidas por el propio organismo en ciertas etapas del crecimiento y desarrollo, entre otros) y por factores exógenos (por ejemplo otros organismos como las bacterias o virus, el medio ambiente, los alimentos, etc.). Esta es una de las dimensiones que se ha estudiado más con relación a la salud, sobre todo por el modelo médicohegemónico, por lo que, en muchas ocasiones, ha sido tomada casi como la única - o al menos la principal - para explicar dicho fenómeno, así como la enfermedad.

La dimensión social puede dividirse en dos: la micro y la macro. La esfera microsocial se refiere principalmente a las relaciones interpersonales que el sujeto establece con sus familiares, vecinos, compañeros de trabajo, amistades, parejas, etc. y también se encontrará determinada por factores internos (por ejemplo, los 
intereses, las necesidades, las preferencias del sujeto, entre otros) y por factores externos.

En cuanto a la macrosocial, ha sido estudiada principalmente a partir de la teoría marxista, planteando que los procesos de salud-enfermedad (PSE) son resultado del modo de producción dominante en cada sociedad, considerando

lo social como el elemento que permite explicar la problemática de salud de los grupos sociales, así como los demás aspectos con los cuales se relaciona, por ejemplo la esperanza de vida, la conciencia sobre los problemas de salud, las características de los servicios médicos y el acceso real a ellos, etcétera. (Soriano, 1999:9)

Lo anterior parte de la observación de que los PSE se distribuyen de manera diferencial entre los diversos grupos que conforman una sociedad, por lo que cuestiona su etiología en factores únicamente biológicos y la relaciona con las condiciones materiales de existencia como el factor determinante, llegando a la conclusión de que la salud se ha convertido también en una mercancía de consumo a la que no todos tienen un acceso equitativo debido a las desigualdades sociales producidas por la estructura de clases y la lucha que se da entre éstas.

La dimensión psicológica se refiere tanto a aquellos procesos conscientes e inconscientes que han conformado la personalidad del sujeto a partir también de factores externos e internos, como a los procesos cognitivos por medio de los cuales el ser humano percibe, interpreta y representa su mundo, siendo el ámbito de lo simbólico uno de los más importantes a considerar en el trabajo a través del arte en el área de la salud.

Sería complicado exponer a profundidad en este artículo el sustento teórico desde el cual parto para estudiar esta dimensión, debido al límite de extensión del texto; sin embargo, remito al lector a consultar las obras de Freud, Jung, Vigotsky y Piaget con el fin de que se forme una idea al respecto.

Por último, la dimensión espiritual quizá sea la que resulte más controversial de este texto, pues casi siempre se le ha equiparado con la religiosidad, con dogmas o con algún culto; sin embargo, quisiera referirme a ella, más allá de su institucionalidad, como una necesidad de trascendencia en el ser humano que lo lleva a una búsqueda incesante de alcances que van más allá de su individualidad, que incluso pueden hacerlo consciente de la unión que existe entre todos los seres del universo, mitigando con ello su soledad en el mundo y su pequeñez ante el cosmos, tal como lo menciona Alexander Lowen, "nuestra espiritualidad se deriva de esta sensación de unión con una fuerza o un orden superior a nosotros mismos"(Lowen, 2010:15). A partir de esta dimensión es que ha construido mitos que lo conectan con fuerzas mayores representadas muchas veces como dioses, pero que no son más que proyecciones de esa necesidad de trascendencia.

Llama mi atención que en la mayoría de los textos sobre salud esta es la dimensión que menos se toma en cuenta, con excepción de algunos clasificados en el modelo alternativo, por lo que me pregunto si en verdad resulta insignificante para 
dicho fenómeno. Desde mi punto de vista no es así y, de hecho, considero que muchas de las enfermedades tienen su raíz en un descuido de lo espiritual, no sólo por parte del sujeto individual, sino sobre todo por parte de nuestras sociedades en la actualidad, ya que se enfocan principalmente en cubrir las necesidades materiales por medio del consumo excesivo.

Mi postura con respecto a la salud, tal como lo mencioné desde un inicio, es que se trata de un fenómeno complejo multifactorial y multidimensional, por lo tanto me parece que cualquier visión que deje de lado algo de ello será incompleta y esto se verá reflejado en la vida de los seres humanos como enfermedad, aunque es cierto que es imposible lograr un estado total de salud, ya que es necesaria una cierta falta para movilizar la energía y la capacidad creativa, aunque esto no significa que se justifiquen las inequidades en salud, resultantes de la desigualdad social.

En cuanto a si la salud puede ser considerada un estado, un proceso o un recurso, pienso que es las tres. Es un estado porque se refiere a algo que está, que existe en todas las dimensiones; es un proceso porque es resultado de las relaciones que se dan entre todas las dimensiones y factores que giran a su alrededor; y es un recurso porque permite poner en marcha lo necesario para mejorar cualquiera de las dimensiones, así como incidir en cualquiera de los factores.

Como resultado de las reflexiones anteriores, definiría a la salud como un estado del ser humano en las dimensiones biológica, social, psicológica y espiritual que, al mismo tiempo, es un proceso derivado de las relaciones que se dan entre ellas y con los factores externos e internos del sujeto y que puede convertirse en un recurso para incidir en cualquiera de dichos aspectos.

\section{LA PROMOCIÓN DE LA SALUD Y EL ARTE}

A pesar de que la práctica de la promoción de la salud ha acompañado al ser humano prácticamente a lo largo de toda su evolución, no fue sino hasta 1978 - con la meta internacional "Salud para todos en el año 2000" acordada en la Conferencia Internacional sobre Atención Primaria de Salud llevada a cabo en Alma-Ata, exURSS - que se instauró como un campo disciplinar.

En 1986, en Canadá, se llevó a cabo la Primera Conferencia Internacional sobre la Promoción de la Salud como un primer intento de sistematización de las experiencias que se desprendieron de la Declaración de Alma-Ata, con el fin de unificar criterios internacionales que se reflejaran en políticas públicas encaminadas al logro del propósito acordado.

Según la Carta de Ottawa (documento desprendido de la conferencia llevada a cabo en Canadá), la promoción de la salud consiste en

proporcionar a los pueblos los medios necesarios para mejorar su salud y ejercer un mayor control sobre la misma. Para alcanzar un estado adecuado de bienestar físico, mental y social un individuo o grupo debe ser capaz de identificar y realizar sus aspiraciones, de satisfacer sus necesidades y de cambiar o adaptarse al medio ambiente. La salud se percibe pues, no como 
el objetivo, sino como la fuente de riqueza de la vida cotidiana. Se trata por tanto de un concepto positivo que acentúa los recursos sociales y personales así como las aptitudes físicas. Por consiguiente, dado que el concepto de salud como bienestar trasciende la idea de formas de vida sanas, la promoción de la salud no concierne exclusivamente al sector sanitario. (OMS, 1986)

A pesar de los esfuerzos internacionales por unificar las medidas para alcanzar los objetivos propuestos, la dificultad de llevar a la práctica la promoción de la salud se relaciona con la diversidad de definiciones que se han construido en torno al concepto mismo de salud, tal como lo mencioné en el apartado anterior.

Sin embargo, quisiera centrarme en la visión Emancipatoria de la promoción de la salud con el fin de sustentar la experiencia que describiré más adelante sobre el arte como herramienta para la práctica en este nuevo campo disciplinar.

Para el modelo emancipatorio, la salud es "la capacidad del sujeto individual o colectivo de mirar al pasado para gobernar el presente para la construcción de futuros viables"(García:4), es un recurso para llevar a cabo la construcción y puesta en marcha de proyectos de vida, determinado por el grado de desarrollo de las capacidades humanas (sapiens/pensar, faber/trabajar, hacer o crear, ludens/imaginar, eros/motivarse o apasionarse y política/tomar decisiones), así como la capacidad de utilizar los capitales hacia el cumplimiento de aspiraciones (Chapela, 2001:59-69). Los elementos teóricos más importantes de este enfoque son: capacidades humanas, capitales, habitus, desarrollo de autonomía, empoderamiento, corporeización.

A partir de lo anterior, las acciones en promoción de la salud desde este enfoque estarán centradas en

identificar vínculos entre la materialidad y la subjetividad inherentes al cuerpo individual y colectivo; a identificar los mecanismos de las agencias hegemónicas para subordinar la salud; a entender mejor sus procesos de invasión del cuerpo-territorio; a identificar y entender la realidad, el deseo y la posibilidad; a buscar formas para devolver y desarrollar las capacidades humanas saludables; a abrir acceso a los recursos y a cambiar las inscripciones del poder en los cuerpos individuales y colectivos. (Chapela, 2007)

Desde mi perspectiva, el desarrollo de la creatividad - relacionada con las capacidades humanas faber y ludens, pero que impacta a las demás - es indispensable para el trabajo en promoción de la salud desde este enfoque, pues

poco a poco, quienes se involucran con el cambio, entienden que es imperativo dejar de lado los enfoques evangelizadores, que la mayor ganancia no es enseñar a sino aprender de y promover el cambio junto a. Haber puesto al sujeto en el centro del debate permite re-valorizar las posibilidades inmensas de cambio social gestionadas desde y por los propios sujetos hacia quienes el cambio está destinado. (Heyaca, 2008:5) 
ya que así pueden dibujarse a sí mismos proyectos de vida distintos a los experimentados en su pasado - determinados fuertemente por diversos factores tanto de índole micro como macrosocial -, por lo que a través de ella pueden pensarse en alternativas para transformar el mundo externo e interno, pues la capacidad creativa

no sólo tiene como propósito "recordar" algo, como un acto de memoria, sino que tiene como fin algo más que el solo hecho de reproducir algo del pasado; tiene como función otra meta: reinterpretar al mundo de manera diferente. (García, 2006:32-33)

Una de las formas para desarrollar la creatividad es el arte, pues

es creación y expresión que contribuye efectivamente a reafirmar la identidad [...] reafirmar la identidad es un requisito necesario para asegurar a los [sujetos] en situación de vulnerabilidad social su capacidad de proyectarse modelos de futuro (capacidad que dicha situación frecuentemente inhibe), su derecho humano básico a soñar con un futuro superador del presente donde puedan percibir y defender su propio lugar dentro del cambio que sueñan ver realizado. El arte es, entonces y desde el punto de vista de las subjetividades y en el contexto de una democracia participativa, un vehículo poderosísimo de promoción de los derechos humanos. (Heyaca, 2008:5-6)

En segundo lugar, el desarrollo de la creatividad puede facilitar que los sujetos experimenten que la construcción de ese futuro, de ese proyecto, está en sus manos - lo cual puede ser casi de manera literal al pedirles que plasmen en un objeto (pintura, collage, escultura o modelado, instalación, etc.) este mundo posible -, permitiendo con esto el tránsito hacia el empoderamiento, además de que

al crear reflexivamente a través del arte, proyectan su interior hacia el exterior: cuentan, hablan, denuncian, sueñan, en medio de un proceso liberador de su ser [...] Así, la propia historia personal se vuelve una retórica compartida con otras historias personales con las cuales existen puntos de contacto esenciales [...] De allí, los sujetos logran romper la tendencia al aislacionismo [...] para pasar a reflexionar junto a otros y críticamente sobre su posición (compartida) dentro de un contexto social mayor (compartido también). Esto refuerza la autonomía crítica y, con ello, la autoestima; operación que conduce a una mayor confianza propia, autonomía personal y sentido del propio ser en el mundo. Esta confianza es el puntapié para involucrarse críticamente en la construcción social. (Heyaca, 2008:6-7)

Por otro lado, el desarrollo de la capacidad creativa facilita la resolución de conflictos, al permitir pensar en diversas alternativas para enfrentarlos, tanto de manera individual como colectiva. Se trataría, pues, de ponerse tantos "sombreros" como se haga necesario para pensar en los problemas, desde tantos lugares como sea posible 
hasta encontrar aquella opción que resulte más factible, viable y eficaz, logrando con ello, por un lado, enfrentar los obstáculos que ya se tienen para empezar a poner en marcha el proyecto de vida imaginado y, por otro, prever los que pudieran aparecer en el futuro.

La promoción de la salud a través del arte implica varios retos, uno de los cuales se refiere a que los estudiantes se enfrentarán con la forma de entender a la salud y a la enfermedad por parte de las instituciones y la sociedad, así como con las prácticas que esto conlleva, invitándolos a pensar en nuevas formas de intervención que no siempre son aceptadas y que muchas veces son desvalorizadas por no ofrecer posibilidades de lucro para las grandes empresas. Por lo tanto, implica ir contracorriente con un modelo hegemónico que estudia a la salud desde un punto de vista, casi exclusivamente, biológico y que tiende a mercantilizarla cada vez más.

Sin embargo, de esto trata la creatividad: de imaginar diferentes modos de ver la realidad, formas distintas de experimentarla y explicarla, así como de idear otras formas de resistencia y de lucha frente a lo hegemónico, es parte del desarrollo mismo de esta capacidad el romper con lo establecido, con lo dado y buscar lo Otro, aquello que no hemos visto, o no hemos probado o no hemos inventado aún.

Por lo tanto, se vuelve indispensable cambiar el lugar de los estudiantes de objetos pasivos de la educación a sujetos activos autónomos en la construcción de su aprendizaje, que los transformen también en sujetos sociales, sujetos políticos, sujetos profesionales capaces de inventar nuevas formas de intervenir en el campo de la salud y de relacionarse con los otros sujetos con quienes trabajarán más adelante en un mundo tan cambiante como es el nuestro en la actualidad.

Con la incorporación del desarrollo de la capacidad creativa, pretendo no sólo presentar a los estudiantes de la Licenciatura en Promoción de la Salud de la Universidad Autónoma de la Ciudad de México nuevas formas de construir su aprendizaje y de aproximarse a su realidad, sino también "sembrar una semilla", provocar un leve cosquilleo, que quizá más adelante pudiera invadir el cuerpo en su totalidad y llevar a un cambio en la intervención en el campo de la salud, que llegue a trastocar a otros sujetos a través de las prácticas profesionales de los egresados con el fin de imaginar más mundos posibles, de diseñar proyectos de vida viables que tengan como base la autonomía, el empoderamiento y el desarrollo máximo de las capacidades humanas porque, desde mi punto de vista, es desde nuestro entorno inmediato que podemos empezar a generar un cambio mayor, y nuestro entorno más inmediato somos nosotros mismos, nuestro interior y, luego, nuestra familia, nuestra calle, nuestra colonia... el mundo.

\section{EL TIRADERO DE "BASURA": UNA PRIMERA EXPERIENCIA DESDE LA PROMOCIÓN DE LA SALUD A TRAVÉS DEL ARTE}

"El arte es una herramienta de cambio efectiva porque la creación es revolución. Nada es igual antes y después de un acto creativo... Crear es poner patas arriba algo, es inventar, es confrontar con lo conocido, es explorar formas nuevas..." (Heyaca, 2008:1) 
En 2008, comenzamos a organizar el Foro Anual de Promoción de la Salud y Encuentro de Estudiantes de la Licenciatura. Francamente nosotros mismos nos vimos sorprendidos y rebasados por la respuesta de la comunidad de todos los planteles ante este evento, pues asistieron muchas más personas (900) de las que creíamos que asistirían (250), lo que le ha dado no sólo un reconocimiento interno importante, sino también por parte del exterior a la universidad y le ha valido mayor apoyo por parte de las diferentes instancias que conforman nuestra institución.

Cada año, la temática ha ido cambiando y en el 2010 versó sobre "Salud, crisis ambiental y derechos sociales", contando con la participación en mesas de debate tanto de especialistas sobre los diversos temas, como de estudiantes y afectados ambientales de diversas zonas geográficas, sobre todo de nuestro país. También se llevaron a cabo talleres simultáneos sobre diversas problemáticas durante los días del evento, para lo cual, los miembros del comité organizador me invitaron a participar con el tema "Residuos sólidos".

Desde que me hicieron llegar la invitación, me sentí muy entusiasmada con la idea, así que de inmediato prácticamente puse "manos a la obra" y me di a la tarea de organizar la sesión: identifiqué los subtemas que podían ser abordados (reciclaje; separación de residuos sólidos; condiciones de vida, salud y laborales de los trabajadores de la basura "pepenadores" - cabe aquí una precisión sobre este término: en México existen diversos grupos sociales que viven de y en la basura, son personas que han construido sus casas de cartón o lámina en los bordes de los tiraderos de basura, que caminan sobre ellos con costales para guardar artículos que consideran todavía valiosos para su reventa, como juguetes, joyería, cartón, PET, hasta ropa, siendo éste su único medio de sustento. Se encuentran organizados por familias y están liderados por una persona que es la encargada de negociar con el gobierno para mantener su comunidad y su "derecho" a continuar en dicho tiradero para beneficiarse de lo que en él encuentren. Este tema presenta una gran complejidad que es imposible abordar en el presente artículo debido al límite de extensión, sin embargo resulta importante esta aclaración ya que es un fenómeno sociocultural que no se da en todos los países, ni siquiera latinoamericanos, además de que algunas de las obras que se mencionarán posteriormente hacen referencia a comunidades de pepenadores -; trabajo infantil y derechos de los niños; basureros tóxicos y desigualdad entre países, etc.), busqué artículos o capítulos de libros claves para brindar un panorama general de la problemática con el fin de generar la discusión en torno a ellos.

Además de lo anterior, supe también que ésta era una grandiosa oportunidad para comenzar a poner en práctica la promoción de la salud a través del arte, por lo que organicé de tal forma las actividades de la sesión que siempre estuvieran presentes la creatividad y el arte.

Para tal efecto, lo propuse al comité organizador con el fin de que se empezara a construir una instalación sobre el tema desde varias semanas antes del evento (regresando de vacaciones de verano), pues el primer propósito del taller fue el de generar consciencia en la comunidad universitaria sobre la crisis ambiental, en es- 
pecífico en lo que respecta a la generación de residuos sólidos, por lo que era necesario contar con un espacio en el plantel para ir haciendo acopio de residuos sólidos inorgánicos - y limpios (lavados) - que, a su vez, iría tomando forma de "tiradero de basura" para alcanzar este objetivo.

Se realizaron las gestiones necesarias y el 10 de agosto de 2010 comenzó a construirse la instalación en el jardín cultural del plantel Casa Libertad - cabe señalar que ese espacio es compartido con una guardería comunitaria, por ello es que siempre se subrayó la importancia de que los residuos fuesen inorgánicos y que los lavaran antes de depositarlos ahí - con una respuesta inmediata por parte de la comunidad universitaria, pues desde ese mismo día comenzó a aportar residuos.

Cabe señalar que, a pesar de haber colocado en el lugar diversos letreros que explicaban a grandes rasgos lo que se estaba construyendo ahí, hubo reacciones de incomodidad, desagrado y rechazo ante el cúmulo de "basura" (material de reciclaje), lo que culminó en que sin previo aviso ni consulta, un grupo de tres profesores le dieran la orden al personal de intendencia para desecharla.

Así, un viernes por la mañana, llegando al plantel, me percaté de que el material ya no se encontraba, así que pregunté y escuché lo peor: "fue tirado a la basura" así, nada más, ahora con el falso argumento de que podía ser un foco de infección para los niños de la guardería (recuérdese que se trataba de residuos inorgánicos y LIMPIOS). Nadie preguntó, nadie avisó y nadie daba la cara por la decisión.

Los estudiantes de la Licenciatura en Promoción de la Salud estaban al tanto del taller, pues en el lugar se encontraban pegados los carteles con mis datos, así que durante aquél día varios fueron a preguntarme qué había pasado, que dónde podían poner su material, etc., así que les comenté lo sucedido y empezó a generarse un proceso que jamás imaginé que tuviera las dimensiones que cobró: un movimiento estudiantil de lucha por un nuevo espacio para poder recolectar los materiales.

Los estudiantes tomaron en sus manos la organización del taller que ahora ya se ha vuelto proyecto, su difusión, la exigencia a las autoridades del plantel con el fin de que proporcionaran los recursos necesarios para llevarlo a cabo y la instalación de un nuevo "tiradero de basura".

Después de varias semanas entre oficios, discusiones, reclamos, etc., los estudiantes de las tres carreras que se ofertan en el plantel (Promoción de la Salud, Ciencias Políticas y Administración Urbana e Ingeniería en Sistemas Electrónicos y de Telecomunicaciones), lograron que se nos asignara un nuevo espacio, a partir de lo cual ellos se apropiaron mucho más del proyecto y se generaron gran cantidad de ideas sobre cómo hacer más sustentable a Casa Libertad.

Logramos reunir gran cantidad de material y, sobre todo, de inscritos al taller a partir de los obstáculos que se suscitaron, pues fue gracias a ello que la comunidad comenzó a hacerse más consciente del problema y a interesarse por plantear propuestas, así que hasta la "basura" que algunas personas lanzaron sobre el proyecto pudo ser transformada en interés, compromiso y participación por parte de los estudiantes principalmente, quienes incluso diseñaron el cartel para el taller que se muestra a continuación: 


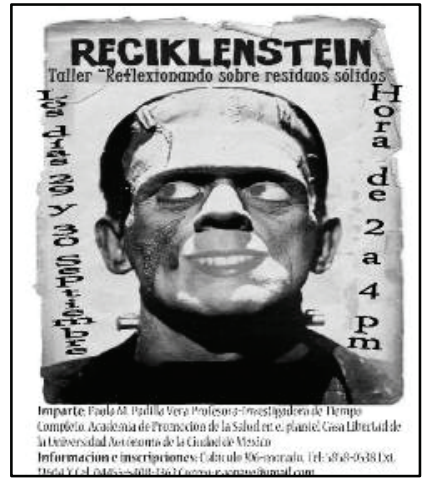

Imagen 1. Cartel del taller diseñado por estudiantes

El taller "Reflexionando sobre residuos sólidos" se llevó a cabo el 28 y 29 de septiembre de 2010 en el plantel Casa Libertad de la Universidad Autónoma de la Ciudad de México.

Iniciamos con la lectura de algunos textos que abordan diversas problemáticas, tales como la separación de residuos sólidos, la desigualdad social y los basureros tóxicos, el perfil socioeconómico de los pepenadores, trabajo infantil entre los pepenadores, entre otros. La idea era sensibilizar a los asistentes ante la problemática de la crisis ambiental, la salud y los derechos sociales, aterrizándola específicamente en el tema del taller, además de contextualizarla y sentar las bases para un lenguaje común.

La idea principal - y de fondo - que atravesó el taller fue la de que el término "basura" es uno que adquiere diversos significados dependiendo del contexto dentro del cual se hable pues, por ejemplo, para la mayoría de las personas una botella de plástico puede ser desechada fácilmente, mientras que para otras se ha convertido en un medio de sustento, por lo que van recolectándolas por las calles.

Otro ejemplo es el que sucede en la Central de Abastos de la Ciudad de México, en donde diariamente se desechan toneladas de residuos, entre los que podemos observar a decenas de personas "pepenando" lo que otros han tirado, incluyendo frutas y verduras para, después, venderlas en los tianguis (mercados ambulantes que se instalan en las calles durante ciertos días de la semana) o en alguna esquina de la ciudad.

¿Qué es la basura entonces? Podría decirse que una construcción social que la mayoría de las veces nos exime de nuestra propia responsabilidad sobre los residuos que generamos a partir de nuestros hábitos de consumo, pues - al considerarlos como tal - simplemente nos deshacemos de ellos acrecentando así el problema mundial de la crisis ambiental y sin detenernos a reflexionar sobre lo que ese simple acto genera como consecuencias.

A pesar de que hace apenas unos años el Gobierno del Distrito Federal aprobó la nueva Ley de Residuos Sólidos, en la que se estipula como una obligación ciudadana la de entregar a los camiones recolectores la basura separada, esto no ha podido consolidarse aún como un hábito por varios motivos:

1. Existen muchas zonas en las que los camiones recolectores no poseen cabinas separadas, por lo que vuelve a juntarse en ellos.

2. Debido al punto anterior, la sociedad no le encuentra sentido a la separación de sus residuos en casa, por lo que ha vuelto a juntarla en el mismo bote o bolsa.

3. No se aplican las sanciones estipuladas para quien no lleve a cabo esta medida. 
Desde mi perspectiva, esto refleja, por un lado, la falta de concienciación en torno a la crisis ambiental - a pesar de que la Ciudad de México es una de las más contaminadas del mundo $-\mathrm{y}$, por otro y por lo tanto, la evasión de la propia responsabilidad ante dicha problemática.

Así pues, cabe la pregunta sobre ¿qué podemos hacer con eso que llamamos "basura" que no sea sólo tirarla? ¿qué alternativas podemos construir?

Me interesaba sobre todo que el taller no se quedara sólo en el aprendizaje de la separación de los residuos, sino que se pudieran expresar a través de ellos las conclusiones sobre el mismo, por lo que durante la sesión presenté una serie de imágenes y videos que mostraban formas alternativas para hacer uso de la "basura", desde la elaboración de ceniceros con latas de refresco hasta construcciones de casas con PET, pasando por el "trash-art", con el fin de generar curiosidad entre los asistentes pero, sobre todo, para sensibilizarlos e invitarlos a re-pensar y re-significar el material que se encontraba en "El tiradero", proponiéndoles expresar sus conclusiones de las discusiones de los temas y del taller en general, de manera creativa a través de la construcción de objetos artísticos con eso que, en otro contexto, sería considerado "basura".

Al final del día 28, entonces, se mostró el material visual y se les dio la instrucción a los equipos de pensar juntos cómo expresarían sus conclusiones utilizando el material de "El tiradero".

El 29 habíamos acordado trabajar en el Jardín Cultural de Casa Libertad para tener más espacio que en un salón de clases, así que poco a poco fueron llegando los equipos y se les dio la instrucción de recoger su material y comenzar a trabajar en lo que habían acordado previamente.

Durante la sesión, varios estudiantes que inicialmente se encontraban en dicho jardín platicando, se fueron incorporando en el trabajo de los equipos - incluso unos hicieron su propio equipo - por lo que hubo más participación y asistencia que el día anterior.

Desde lo alto, en el pasillo superior que rodea el jardín, la gente se encontraba observando el trabajo del taller y tomando fotos.

Las creaciones fueron diversas, todo realizado con los materiales recopilados, como puede observarse en las siguientes imágenes:

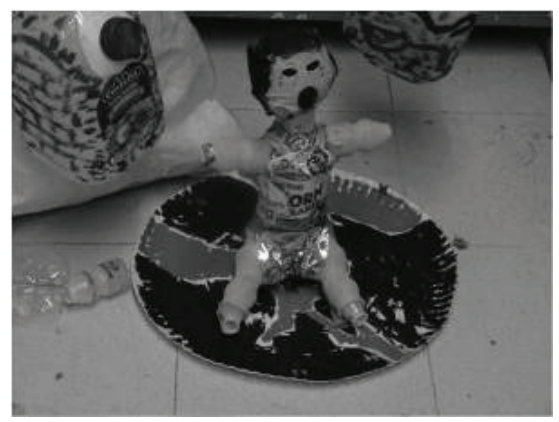

Imagen 2. "El bebé neoliberal": a decir de los autores, expresa el consumo exacerbado, así como nuestra irresponsabilidad con el manejo de los residuos que éste conlleva (elaborado con diferentes residuos). 

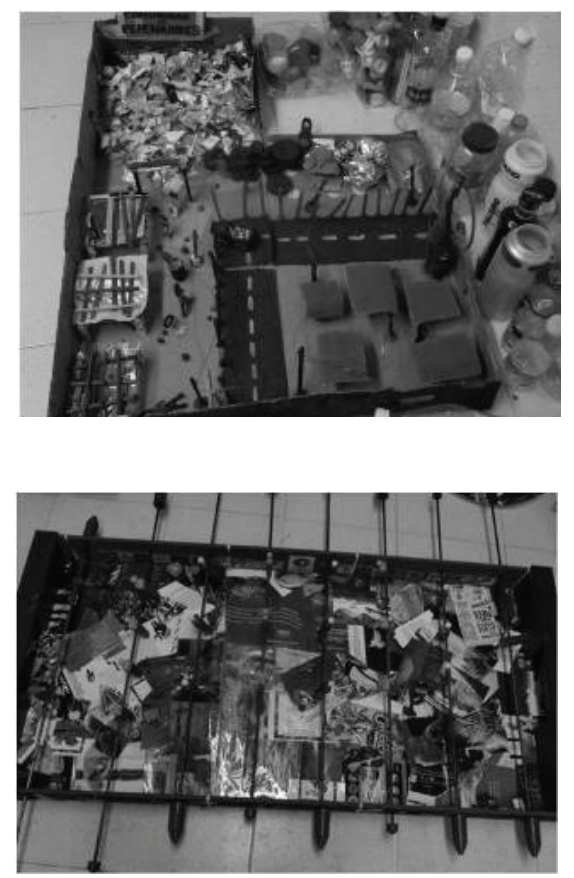

Imagen 3. "Comunidad de pepenadores": instalación miniatura elaborada con diferentes residuos y que muestra las condiciones de vida de dicho grupo social.

Imagen 4. "Pepenadores": elaborado con la estructura de un futbolito, la base fue forrada a manera de collage, representando los tiraderos de basura en los que trabajan los pepenadores, quienes están representados por los muñecos que se encuentran en las varas de metal.

Por último, se montó una instalación del taller integrando todos los trabajos realizados que, al concluir el Tercer Foro Anual de Promoción de la Salud, los asistentes pudieron observar, recibiendo comentarios muy positivos no sólo sobre el producto, sino sobre el proceso en general, además de llevar a la reflexión en torno a cómo utilizar esta misma herramienta - el arte - en algunos otros proyectos de promoción de la salud, sobre todo comunitarios.

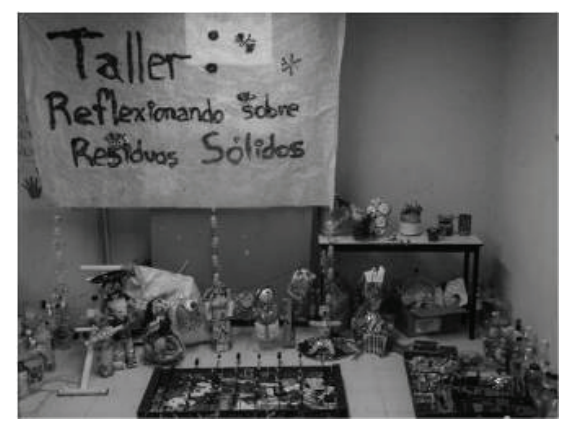

Imagen 5. Exposición de las obras construidas por los asistentes al taller "Reflexionando sobre residuos sólidos" 
Por otro lado, algunas conclusiones de los asistentes reflejan la utilidad del arte para generar nuevas formas para re-pensar, re-plantear y re-significar las problemáticas sociales, como ésta, con el fin de expresarlas y transformarlas de manera creativa.

En conclusión, el proceso fue muy enriquecedor tanto para las que coordinamos el taller, como para los asistentes al mismo y la comunidad universitaria en general, pues nos permitió:

- Generar consciencia sobre la problemática.

- Plantear propuestas para asumir nuestra responsabilidad ante ella.

- Pensarla y significarla de una forma muy distinta.

- Expresarla de manera alternativa, a través del arte.

- Integrar a la comunidad universitaria de diversas licenciaturas y planteles de la Universidad Autónoma de la Ciudad de México. salud.

- Considerar al arte como una herramienta para la promoción de la

\section{A MANERA DE NOTA FINAL...}

Como se pudo observar en las páginas anteriores, el trabajo a través del arte permite abordar la salud desde las diferentes dimensiones y factores que en ella intervienen; en el caso aquí descrito, la reflexión giró en torno a la crisis medioambiental y los derechos sociales en lo relacionado con los residuos sólidos, posibilitando un proceso de resignificación sobre dichos temas y, por lo tanto, el planteamiento de propuestas para atacar esta problemática.

En la dimensión biológica, el factor medioambiental juega un papel sumamente importante ya que puede generar diversas enfermedades que van desde cuadros infecciosos hasta cáncer, tal como pudo observarse en algunas de las obras elaboradas por los estudiantes durante el taller. Sin embargo, el arte no fue únicamente una herramienta que permitió a los asistentes expresar de manera simbólica dicha problemática, sino también reflexionar sobre ella y proponer alternativas para reutilizar aquello que comúnmente llamamos "basura"; es decir, llevar a cabo un proceso de resignficación.

En la dimensión social, encontramos que el factor medioambiental se cruza con el de la desigualdad, por varios motivos: por un lado, en la Ciudad de México, los tiraderos suelen estar en zonas marginadas en las que los grupos que ahí habitan lo hacen bajo condiciones de existencia deplorables que determinan sus niveles de salud y bienestar; por otro lado, las personas que viven de lo que pueden recoger en los tiraderos, no cuentan con los servicios públicos indispensables para mejorar sus condiciones de existencia, por lo que se vuelven vulnerables a contraer múltiples enfermedades, dado que la terminación de su jornada laboral no acaba con su contacto con la basura pues la mayoría de ellos construyen casas de lámina en las orillas de los tiraderos, por lo que, prácticamente las 24 horas del día se encuentran en contacto con ella,; por último, tenemos que esta misma desigualdad se da entre países, pues aquellos que producen desechos tóxicos, les arrendan un espacio a otros del tercer mundo para utilizarlos como almacenes o tiraderos, deslindándose así de 
toda responsabilidad sobre sus consecuencias en la salud de la población. En este sentido, por medio de las actividades del taller no sólo pudo reflexionarse en torno a esta problemática y expresarla en algunas de las obras que los estudiantes construyeron, sino que también pudieron pensarse propuestas para hacerle frente. Entre otras, se sugirió que se lleven este tipo de talleres a comunidades de pepenadores con varios propósitos: primero, generar reflexiones en torno a la problemática en general; segundo, generarlas sobre sus propias condiciones de vida; tercero, pensar colectivamente en soluciones y, cuarto, ofrecer capacitaciones sobre, por ejemplo, construcción con PET tanto para que hagan sus propias viviendas con esta técnica como para que pudiera convertirse en su actividad laboral y de supervivencia principal.

En cuanto al problema de fondo, que es el de la desigualdad, se propuso no sólo mostrar en una exposición las obras que se elaboraron en el taller junto con algunas reflexiones para invitar a los observadores a una reflexión en torno al tema, sino también que se lleven este tipo de talleres a la mayor parte posible de espacios (tales como escuelas, centros comunitarios, hospitales, centros de salud, etc.) con el fin de generar consciencia sobre la problemática.

La dimensión espiritual, tal como se mencionó anteriormente, se refiere a ser conscientes de la interconexión con todos los seres del universo y con una búsqueda de trascendencia en el ser humano. Desde mi punto de vista, el factor medioambiental no cabe mejor en otra dimensión como en esta, pues precisamente la pérdida de esa consciencia es lo que nos ha llevado a explotar de forma exacerbada e irresponsable los recursos naturales, a partir de una actitud homocéntrica en la que todo lo demás está para satisfacer las necesidades del ser humano y con las consecuencias que ahora estamos viendo y viviendo ante la crisis medioambiental mundial en la que no sólo ya son insuficientes esos recursos, sino que también los pocos que aún quedan se encuentran en pésimas condiciones. Así, el taller permitió también reflexionar sobre este tema, hacernos conscientes de nuestra responsabilidad ante esta problemática y de que es momento de tomar acción ya. El arte permitió resignificar nuestra propia relación con la naturaleza y ver que no somos separados de ella, sino parte fundamental de la misma, por lo que está en nuestras manos el revertir los daños que, de hecho, nosotros mismos hemos causado debido al consumismo exacerbado en el que vivimos en la actualidad.

Si nosotros somos los que fabricamos armas nucleares, ¿por qué luego tiramos los desechos en los mares?; si nosotros somos los que fabricamos y consumimos refrescos, ¿por qué luego simplemente tiramos la lata pudiendo transformarla en un cenicero o en un lapicero o reciclarla para volver a utilizar el aluminio?; si nosotros somos los que fabricamos envases plásticos para el agua, ¿por qué luego la tiramos, en lugar de construir cuartos o casas con ellos?

Las conclusiones de los asistentes al taller se recopilaron por escrito al finalizar la segunda sesión de trabajo y se refieren, entre otras, a que el arte les permitió expresar, reflexionar y resignificar el tema de los residuos sólidos para hacer consciencia sobre la magnitud de la problemática. Asimismo comentaron que sería indispensable llevar este tipo de actividades a otros espacios con el fin de ir 
construyendo una red que nos haga ser más responsables ante esta crisis medioambiental mundial.

Actualmente, en la universidad se están empezando a gestionar algunos proyectos que se derivaron de lo anterior. Entre otros, las obras elaboradas durante el taller sobre residuos sólidos han sido donadas a casas de cultura de las comunidades vecinas a la universidad con la finalidad de generar consciencia sobre las problemáticas que se abordaron; para el siguiente año está planeándose un taller de elaboración de composta; se está trabajando con una preparatoria en un municipio cercano a la universidad sobre esta misma problemática y bajo esta misma metodología; se está trabajando sobre el proyecto de construcción con PET de aulas faltantes en el plantel y, por último, se elaborará la propuesta de un taller de promoción de la salud a través del arte abierto para la comunidad universitaria y vecina que tendrá como finalidad generar obras artísticas sobre diversas problemáticas (planteadas por los asistentes) en un proceso de reflexión-resignificación-intervención con miras a incidir en diversos ámbitos y niveles de nuestra sociedad, tratando de incorporar con el tiempo a otras instituciones públicas y privadas, tanto para llevar a cabo exposiciones itinerantes de las obras, como talleres.

En cuanto al arte como herramienta para la promoción de la salud, los asistentes al Tercer Foro Anual de Promoción de la Salud y Encuentro de Estudiantes de Licenciatura de la UACM reconocieron la importancia de incorporarlo en las actividades académicas de algunos cursos, por lo que se han estado llevando más actividades basadas en la metodología aquí propuesta, relacionadas ahora con otras temáticas, tales como "La diversidad de concepciones sobre salud/enfermedad" o "Los Derechos Económicos, Sociales y Culturales y los establecimientos, bienes y servicios de salud". Sin duda, la experiencia que aquí se ha expuesto, al ser la primera de una metodología de investigación-intervención para la promoción de la salud de este tipo, ha dejado ver los puntos que aún hace falta afinar para seguir desarrollándola y promoviéndola. 


\section{REFERENCIAS BIBLIOGRÁFICAS}

CHAPELA, M. (2001) "Promoción de la salud. Siete tesis para el debate". En Cuadernos médicos sociales. México, Universidad Autónoma Metropolitana.

CHAPELA, M. (2007) "Promoción de la salud. Un instrumento del poder y una alternativa emancipatoria”. En Temas y desafios en salud colectiva. Argentina, Lugar Editorial.

GARCÍA, E. (2006) La psicología de Vigotsky en la enseñanza preescolar. México, Trillas.

GARCÍA, D. (2006) "Introducción del enfoque emancipatorio de la promoción de la salud". En Documento inédito elaborado para el curso de Introducción a la Promoción de la Salud, de la Licenciatura Promoción de la Salud en la Universidad Autónoma de la Ciudad de México. México, Universidad Autónoma de la Ciudad de México.

HEYACA, M. (2008) Arte, identidad e inclusión social. Argentina, idebate.ñ. http://workserver.idebate.org/es_clone/

LOWEN, A. (2010) La espiritualidad del cuerpo. Madrid, Paidós.

OMS. (1986) Carta de Ottawa para la Promoción de la Salud. Ginebra, Organización Mundial de la Salud.

SORIANO, R. (1999) Capitalismo y enfermedad. México, Plaza y Valdés editores. 